\title{
Dynamic security issues of autonomous power systems with increasing wind power penetration
}

Margaris, I.D.; Hansen, Anca Daniela; Cutululis, Nicolaos Antonio; Sørensen, Poul Ejnar; Hatziargyrio, N.D.

\author{
Published in: \\ EWEC 2010 Proceedings online
}

Publication date:

2010

Document Version

Publisher's PDF, also known as Version of record

Link back to DTU Orbit

Citation (APA):

Margaris, I. D., Hansen, A. D., Cutululis, N. A., Sørensen, P. E., \& Hatziargyrio, N. D. (2010). Dynamic security issues of autonomous power systems with increasing wind power penetration. In EWEC 2010 Proceedings online European Wind Energy Association (EWEA).

\section{General rights}

Copyright and moral rights for the publications made accessible in the public portal are retained by the authors and/or other copyright owners and it is a condition of accessing publications that users recognise and abide by the legal requirements associated with these rights.

- Users may download and print one copy of any publication from the public portal for the purpose of private study or research.

- You may not further distribute the material or use it for any profit-making activity or commercial gain

- You may freely distribute the URL identifying the publication in the public portal 


\title{
Dynamic security issues of autonomous power systems with increasing wind power penetration
}

\author{
I. D. Margaris ${ }^{1}$, A. D. Hansen ${ }^{2}$, N. A. Cutululis ${ }^{2}$, P. Sørensen ${ }^{2}$, N. D. Hatziargyriou ${ }^{1,3}$
}

\begin{abstract}
Dynamic security of autonomous power systems has become a challenge due to increasing levels of wind penetration during the last years. The special features of non-interconnected power systems make security issues rather critical and operation of wind farms as conventional power plants is becoming a necessity as wind turbines replace conventional units in the production side. This paper describes the study case of Rhodes island, in Greece, where rapidly increasing wind penetration has started to impose serious security issues for the immediate future. Three wind turbine technologies namely Doubly Fed Induction Generator (DFIG), Permanent Magnet Synchronous Generator (PMSG) and Active Stall Induction Generator (ASIG) - are being analyzed regarding ancillary services. Results from a wide range of investigations including power fluctuations, fault rife-through issues and power control services are presented and discussed. The response of the different wind turbine technologies during wind variations, grid faults and frequency deviations is being analyzed. The results prove that ancillary services provided by wind farms in the future can ensure secure and reliable operation of power systems despite the high levels of penetration. The power grid of the island, including speed governors and automatic voltage regulators, was simulated in the dedicated power system simulation program Power Factory from DIgSILENT.
\end{abstract}

Index Terms--wind power penetration, autonomous systems, uninterrupted operation, power fluctuations, frequency control.

\section{INTRODUCTION}

A decade ago, most grid codes considered wind farms as small size dispersed generation and therefore did not require wind turbines to support the power system during transients following grid disturbances. Wind turbines could be disconnected when abnormal grid voltage behavior was detected. The constantly increasing penetration of wind power in the power systems over the last years posed serious concerns regarding the sudden loss of power during grid faults, which could be caused by wind turbines' disconnection,

\footnotetext{
1 Authors are with National Technical University of Athens, School of Electrical and Computer Eng. Electric Energy Systems Lab, \{imarg,nh\}@power.ece.ntua.gr, +30 2107722874

2 Authors are with Risø National Laboratory, Wind Energy Department, P.O. Box 49, DK-4000 Roskilde, Denmark

${ }^{3}$ Author is with Public Power Corporation S.A. Athens, Greece
}

leading possibly to further severe frequency and/or voltage instability. Nowadays grid codes include a wide range of technical requirements that wind farms have to fulfill, [1]

However, in most non interconnected power systems wind power is still considered as dispersed energy and no specific requirements are defined. Ancillary services provided by wind turbines, like fault ride through capability (FRT) and frequency control, are investigated in this article through detailed modelling for all different components of the system. Before wind power penetration limits are expanded in power systems with limited inertia, dynamic security issues have to be carefully investigated. Among the issues studied, power fluctuations resulting from wind speed variations are simulated to analyze the effect on the system frequency.

For the investigations the study case of the Rhodes power system was used. The simulation platform, which was developed, includes three types of conventional generators - gas, diesel and steam units - and three types of wind turbines - Active Stall Induction generator (ASIG), Doubly Fed Induction generator (DFIG) and Permanent Magnet Synchronous generator (PMSG) wind turbines. The response of conventional units, the under/over voltage and frequency protection system, the load dependency on frequency and voltage and the wind turbines' response during events that affect system frequency are some of the key aspects that have to be modelled in detail.

\section{POWER SYSTEM MODELING}

The basic characteristics of Rhodes power system in the reference year 2012 are summarized in Table I in the Appendix. The system includes two power plants and five wind farms. Power system simulation studies for 2012 were based on modified operational data and additional generating units and wind farms, which are expected to be online by the year of study, 2012, [2]. The load scenario, which is presented in this paper, is the maximum wind power penetration scenario (32\% of the load demand). This scenario refers to the winter season, when wind power is significant and load is relatively low. The system inertia under these conditions is restricted, as not so many conventional units participate in the production. Details regarding the modeling of the conventional generating units as well as the wind farms can be found in [3]. 
Three types of conventional units are included in the model: diesel, gas and steam plants. The controllers applied in these units were designed based on built-in standard models available in Power Factory, [4]. The parameters, validated both in Matlab and PSS/E software packages, are presented in [5]. The dynamic models for the system loads connected to Medium Voltage (MV) feeders are using the constant impedance assumption, [6].

Three wind turbine technologies are considered, namely Doubly Fed Induction Generator (DFIG), Permanent Magnet Synchronous Generator (PMSG) and Active Stall Induction Generator (ASIG) based wind turbines, see Figure 1. The installed capacity and type of wind turbine technology used in each wind farm are presented in Table II in the Appendix. The aggregation method used to model the wind farms in the system reduces the complexity without compromising the accuracy of the simulation results, $[7,8]$.

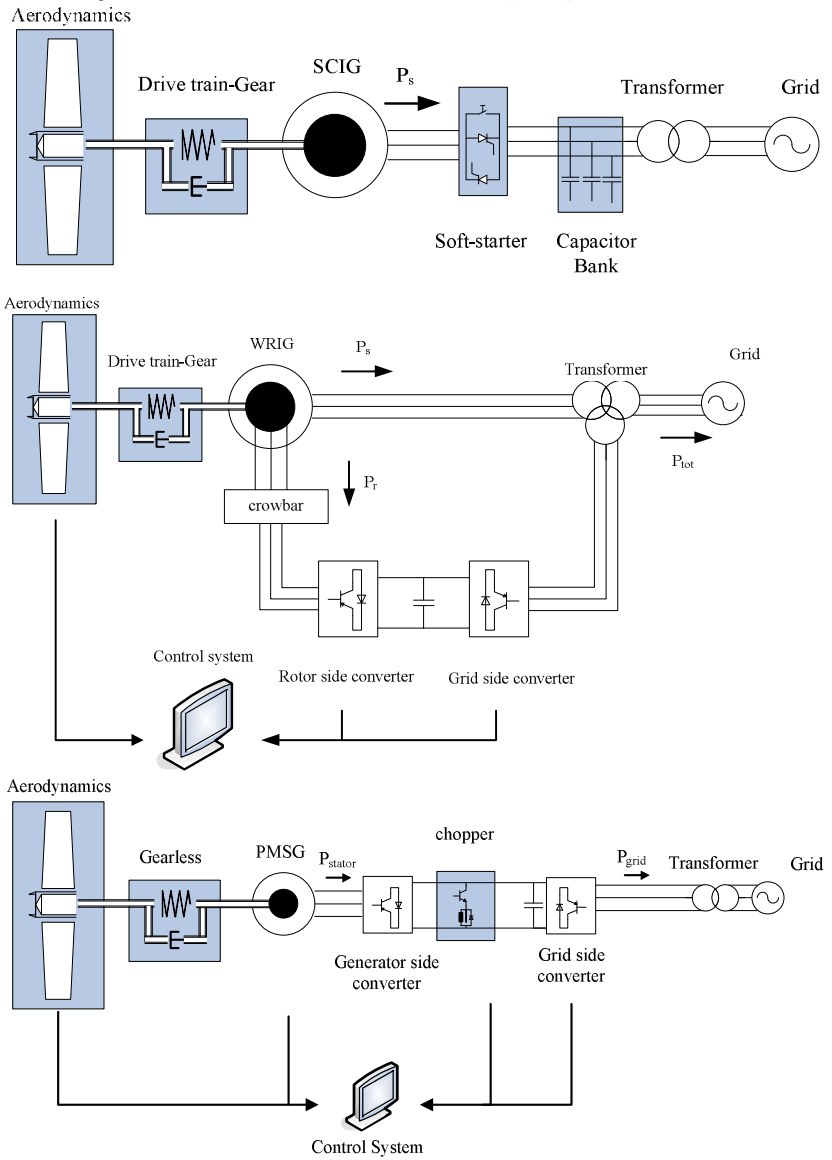

Figure 1. System configuration for three wind turbine schemes: ASIG, DFIG and PMSG wind turbines

The model for the ASIG wind turbine includes submodels for aerodynamics, mechanical components and the squirrel cage induction generator. A two-mass model is used to represent the drive train and the pitch controller controls the active power production through the adjustment of the pitch angle, [9].

The model for the wind farms with DFIG wind turbines is described in detail in [10]. The DFIG system is essentially a wound rotor induction generator with slip rings, with the stator directly connected to the grid and with the rotor interfaced through a back-to-back partialscale power converter, [11].

The model for the PMSG wind turbines includes the mechanical subsystem (i.e. aerodynamics, gearless drive-train and pitch angle control) and the electrical components (i.e. multi-pole PMSG with a full-scale frequency converter and its control). The full-scale frequency converter system controls the speed of the generator and the power flow to the grid. The converter system consists of a back-to-back voltage source converter (generator-side converter and the grid-side converter connected through a DC link), controlled by IGBT switches, [12,13].

\section{POWER FLUCTUATIONS}

Wind speed fluctuations may cause significant wind power fluctuations, although different wind turbine technologies respond more or less soft to the wind speed variations. The summed power fluctuation from all the wind farms is the factor which influences the frequency control in the system. In this study, the Correlated Wind (CorWind) speed simulation tool has been applied to simulate simultaneous wind speed time series at all the wind farm locations. This tool has been developed and validated, based on a substantial database with measurements acquired on land as well as offshore locations, $[14,15]$.

In the maximum wind power penetration scenario, presented in this paper, the fluctuations in the wind may have serious impact on the power system operation due to low system inertia. The system inertia is defined as the total angular momentum, thus the sum of the angular momenta of the rotating masses in the system i.e. generators and spinning loads.

Figure 2 illustrates the wind time series, which have been applied to the wind farms. Due to the wind fluctuations, the system frequency varies between $50 \mathrm{~Hz}$ and $50.25 \mathrm{~Hz}$, which is considered safe for the system operation (see Figure 3). Although the wind speeds in each wind farm may have sudden changes the overall response of the system is satisfactory, and the power outputs from the wind farms seem to counteract each other in the frequency impact. The emergency rate of power undertaken by the conventional units is sufficient to overcome the rapid active power fluctuations produced by the wind farms on the island.

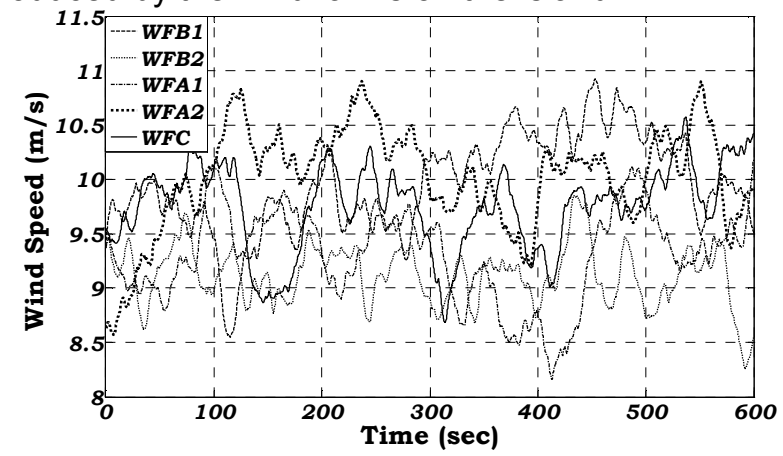

Figure 2. Wind time series applied to the wind farms 


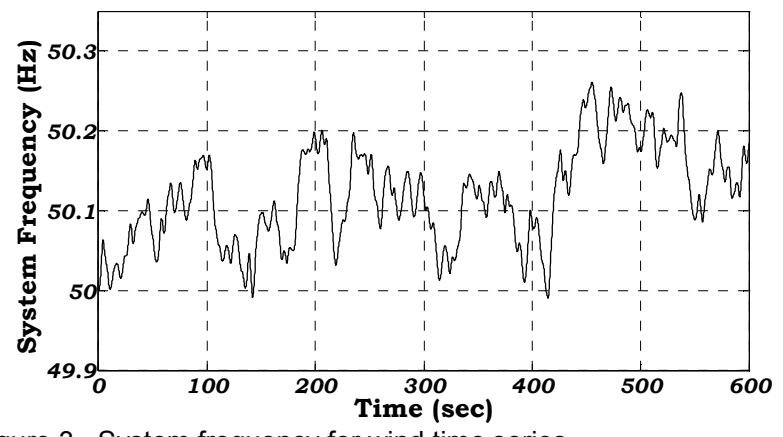

Figure 3. System frequency for wind time series

Figures 4 and 5 illustrate the active power output of each wind farm and the corresponding rotor speeds respectively. In the ASIG wind turbines the correlation between the system frequency and the wind turbine response is very strong while in the DFIG and the PMSG configuration the generator speed is partially decoupled from the system frequency.

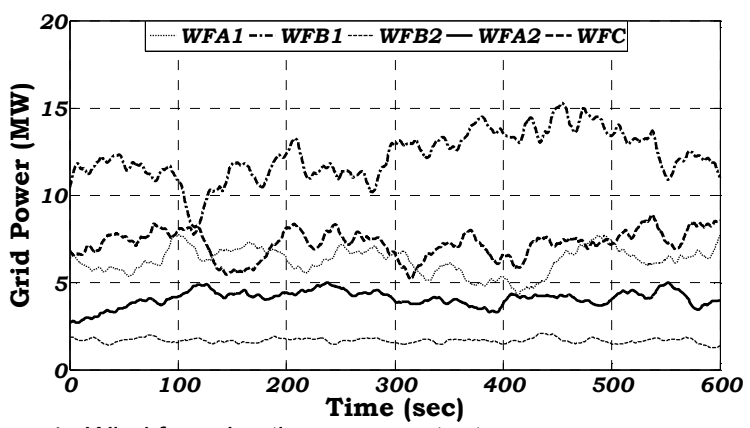

Figure 4. Wind farms' active power output



Figure 5. Generator speeds for the different wind turbine schemes

Despite the fast wind fluctuations, no load is cut off and the frequency is varying in a quite narrow range around nominal $50 \mathrm{~Hz}$. The frequency fluctuations resulting from the wind speed fluctuations are not considered high enough to pose security questions for the power system.

\section{FAULT RIDE THROUGH CAPABILITY}

In case of sudden voltage drop at a grid fault instant, the wind turbines are asked nowadays to stay online and sometimes provide also with reactive power supporting the voltage. Depending on the wind turbine configuration, different control methods have to be implemented in order to ensure uninterrupted operation of the wind farms and prevent further production loss. Figure 6 shows the voltage dips simulated at the Points of Common Coupling (PCC) for each wind farm in case of a three phase fault in a transmission line close to the wind farms.

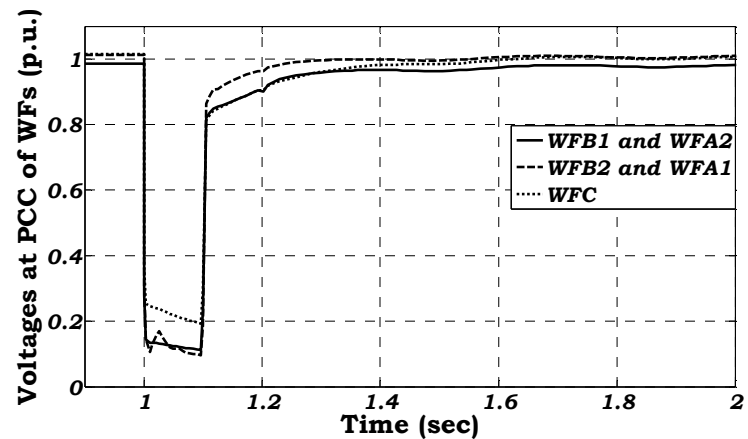

Figure 6. Voltage dips for a three-phase fault

The method of power reduction at the instant of a fault at the grid was implemented for the ASIG wind turbine, [16]. An auxiliary control system substitutes the normal power controller of the wind turbine, which ramps down the mechanical power of the rotor. The restoration of the normal operation is ensured as soon as the voltage at the Point of Common Coupling (PCC) of the wind farm is re-established. Figures 7 and 8 illustrate the behavior of ASWG wind turbine during the fault. After the clearance of the fault, the active power may still be reduced for a few seconds. During the voltage drop, the active power delivered by the generator has to be reduced in order to make the turbine able to ride through the fault preventing possible rotor acceleration.

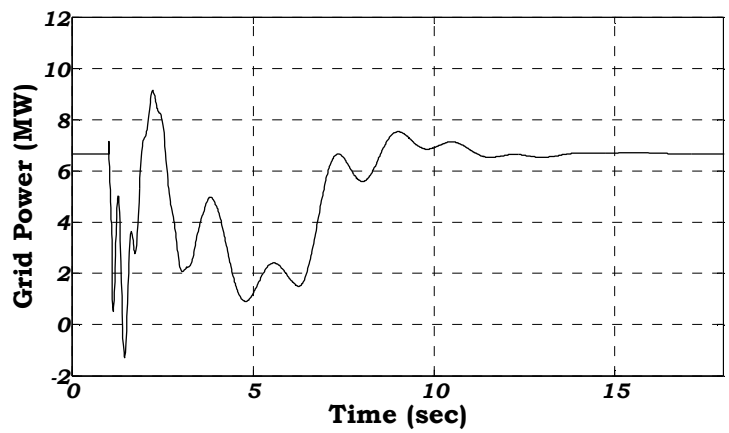

Figure 7. Active power during the fault for a wind farm equipped with ASIG wind turbines

Compared to the sensitive power electronics of variable speed wind turbines, the thermal constants of the induction generator are quite high and the need for protection is reduced despite the high inrush currents, which occur during the fault. The rotor speed of the ASIG wind turbine reflects the power system frequency behavior during the fault (see also Figure 13). When the fault occurs, the speed is initially increased due to the acceleration of the conventional generators and afterwards drops below nominal value. 


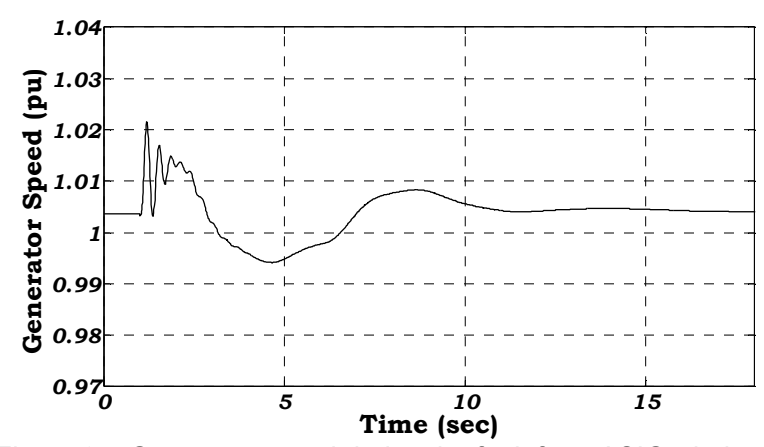

Figure 8. Generator speed during the fault for a ASIG wind turbine

The DFIG configuration requires advanced protection system due to the high inrush stator and rotor currents during grid faults. The rotor side converter is bypassed through the so called "crowbar". The grid-side converter is not blocked at a grid fault and continues its operation as a STATCOM. The controllability is thus improved providing the DFIG with grid voltage support in uninterrupted operation during the transient instant, [17]. The voltage control is also activated in the rotor side converter control system, thus the wind farm manages to provide with additional reactive power supporting the grid voltage.

The response of the DFIG wind turbines in WFA1 during the fault is illustrated in Figures 9 and 10 with or without damping controller. The active power corresponds to the whole wind farm (WFA1).

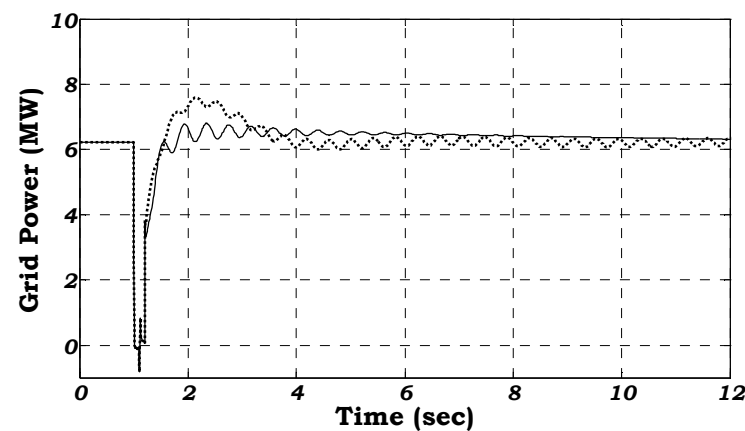

Figure 9. Active power during the fault for wind farm with DFIG wind turbines - solid line, with damping controller, dashed line, without damping controller

The active power delivered by the wind turbine is reduced due to the sudden drop of the voltage, which leads to drop in the stator and rotor flux. The drive train is acting as torsion spring and gets untwisted during fault. The mechanical torque drops slower than the electromagnetic torque and therefore the generator starts to accelerate, see Figure 10.

The crowbar protection system is activated due to the high inrush currents. The rotor side converter (RSC) is blocked and the generator behaves as a conventional squirrel cage induction generator. The damping controller acts directly on the active power reference signal, [11]. This controller damps actively the torsional excitations in the drive train system following the grid fault. In case these oscillations remain undamped, the protection system could be triggered and lead to disconnection of the wind turbine to prevent further mechanical stresses.

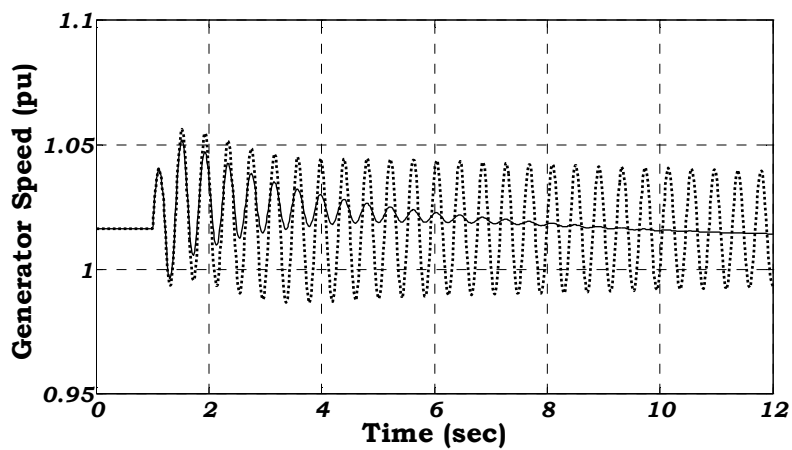

Figure 10. Generator speed during the fault for DFIG wind turbine solid line, with damping controller, dashed line, without damping controller.

PMSG wind turbines can in principle easily accomplish fault ride-through and support the grid during faults due to the presence of the full scale converter. The generator side converter maintains the DC-link voltage around the nominal value while the grid side converter cannot deliver the expected active power during the low voltage at the grid fault instant. The surplus energy is consumed in a resistance through the operation of an additional chopper introduced in the DC-link. The addition of the chopped improves the overall response of the system, [18,19]. Figures 11 and 12 present the fault ride-through capability of the PMSG wind turbines in wind farm WFB2, with and without chopper.

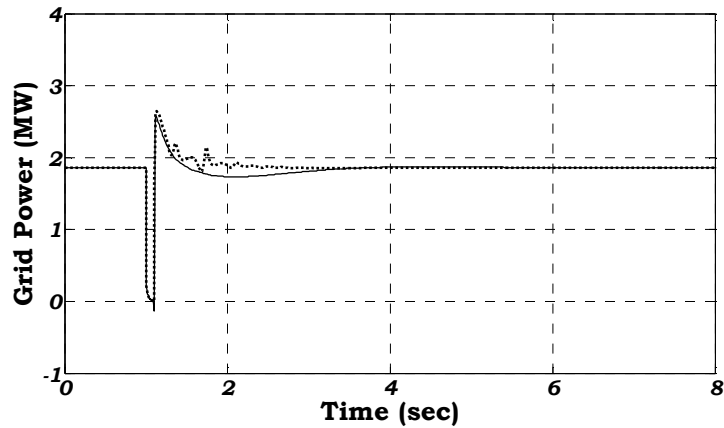

Figure 11. Active power during the fault for wind farm with PMSG wind turbines - solid line, with chopper, dashed line, without chopper

During the low voltage the grid-side converter cannot deliver to the grid the whole active power generated by the generator. The imbalance between aerodynamic and electrical power during the fault causes the acceleration of the generator rotor and the drive train gets untwisted and oscillates. These oscillations are significantly reduced when a chopper is used, see Figure 12. Besides the faster damping of the oscillations, the chopper decreases the rotor accelerations following the fault, minimizing the mechanical stress of the wind turbine. 


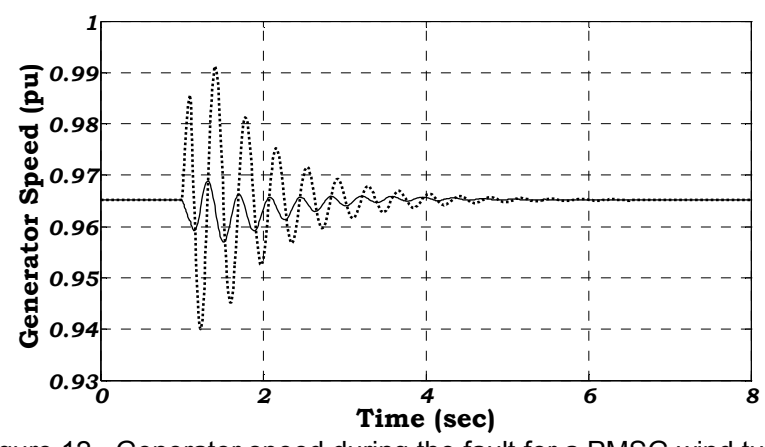

Figure 12. Generator speed during the fault for a PMSG wind turbine solid line, with chopper, dashed line, without chopper

When the wind farms are not able to withstand the low voltage during the fault, they trip for protection reasons. In this case, the voltage dip leads to further wind power production loss resulting to larger frequency drop. In the load scenario under study in this paper the frequency of the system drops down to $47.6 \mathrm{~Hz}$. The under-frequency protection system acts on the loads connected to the medium voltage substations and $65.5 \%$ of the load, i.e. $54 \mathrm{MW}$, is immediately disconnected. On the contrary, when the wind farms are equipped with fault ride through capability, they are able to remain connected to the grid during fault, and the frequency minimum is $49.7 \mathrm{~Hz}$, see Figure 13 . The load shedding is thus totally avoided. The frequency stability as well as the load shedding are improved, making FRT crucial for the secure operation of the system.



Figure 13. System frequency during the fault - solid line, when wind farms are tripping due to low voltage, dashed line, when FRT is available and wind farms stay online

\section{AUXILIARY FREQUENCY CONTROL}

In non interconnected power systems, like Rhodes, sudden generation loss or large load connection lead often to large frequency drop. The primary control function, which occurs during the first $30-40 \mathrm{sec}$ after the event, prevents further frequency drop. The secondary control function of the power system, which takes place several minutes after the event, re-establishes nominal frequency by adjusting the production in the conventional units. In most of the cases secondary control is operated manually by the system operator. The rate, at which the frequency changes, is defined by the total angular momentum of the system, thus the sum of the inertias of the rotating masses in the system.

Large load shedding, which is ordered by the Rate of Change of Frequency (ROCOF) protection system, in order to avoid frequency instability, often occurs to avoid further frequency drop. Under increasing wind power penetration conventional generators get substituted by large wind turbines. The effect on the power system inertia and the availability of inertia response from wind turbines have become key issues for the secure integration of wind energy into the electrical grids. ASIG wind turbines have an inherent response when the system frequency deviates, [20]. On the contrary, variable speed wind turbines (DFIG and PMSG wind turbines) do not contribute to the system inertia.

Auxiliary frequency support provided by modern wind turbines is becoming an urgent requirement, especially in power systems with restricted inertia. In this paper, two frequency control methods, which were applied in the DFIG wind turbine models, are described:

a) Droop control (wind turbine or wind farm level)

b) Inertia Control

The frequency control scheme is illustrated in Figure 14.

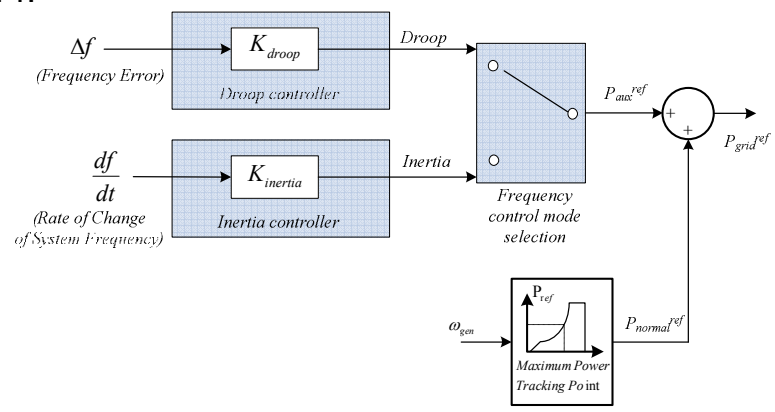

Figure 14. Frequency control scheme for DFIG wind turbines

When droop control is applied, the auxiliary input signal that defines the adjustment in the power production of the wind turbine is the actual error between the measured frequency of the system and the nominal frequency. This control method is based on the primary frequency control applied to conventional generators. The droop control was both applied at the wind turbine level as well as at the wind farm level, where possible communication delays are taken into account.

In Inertia control, the inertial response of the DFIG is restored through an additional loop in the power reference block providing the active power reference signal to the Rotor Side Converter. The DFIG wind turbine adjusts its power output when subjected to frequency deviations, based on the measurement of the rate of change of the frequency. This defines the additional power reference signal, which is added to the normal power reference provided by the Maximum Power Tracking Controller, $[21,22]$.

The loss of the largest conventional unit is simulated and the frequency response is illustrated in Figures 15 and 16 for the different frequency control methods applied at both wind farms with DFIG wind turbines (WFA1, WFA2). The total wind power production is 28.2 MW (34 \%) in total $83 \mathrm{MW}$ of demand. The largest conventional unit in the system produces $21 \mathrm{MW}$ before the protection system acts to take it out of operation - 
this means production loss equal to $25 \%$ of the total demand.

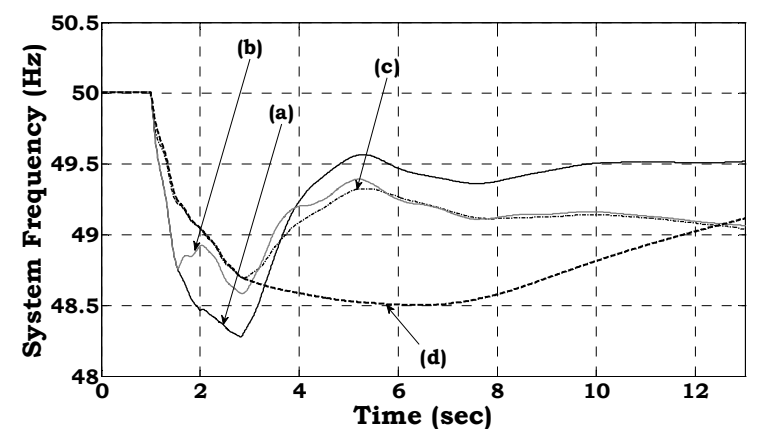

Figure 15. System frequency for largest unit loss when frequency control is applied by DFIGs - (a) No auxiliary control, (b) Droop control on WF level, (c) Droop control on WT level, (d) Inertia control

When the wind farms are not equipped with auxiliary frequency control, the frequency drops below $48.5 \mathrm{~Hz}$ which is the upper zone of the under-frequency protection relay settings acting on the loads (curve (a) in Figure 15). The load shedding in this case is $15.1 \mathrm{MW}-$ $18 \%$ of the total demand - which is not considered accepted in terms of dynamic security, [2]. In all the other cases, where the frequency control is activated in the DFIG wind farms, the load shedding is avoided totally. The maximum frequency drop appears in case (d), where the inertia controller is applied. The optimum frequency drop in terms of minimum frequency is achieved in case (c), when droop control on the wind turbine level is implemented.

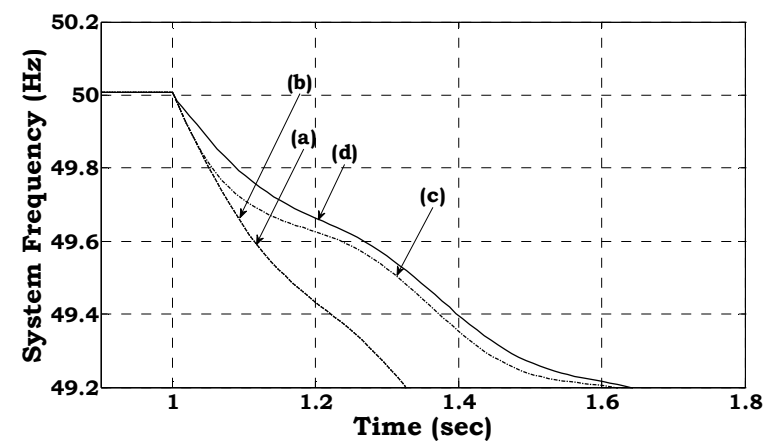

Figure 16. System frequency for largest unit loss when frequency control is applied by DFIGs - Zoom in the first seconds after the event (a) No auxiliary control, (b) Droop control on WF level, (c) Droop control on WT level, (d) Inertia control

The effect of auxiliary frequency control on the maximum rate of change of frequency is illustrated in Figure 16, where the initial drop of the frequency for all cases is zoomed in. This rate is very high as the inertia of the system in this case is low due to the reduced number of conventional generators connected to the system. The rate of change of frequency is close to 5 $\mathrm{Hz} / \mathrm{sec}$ (in absolute value) in case (a). Inertia control manages to reduce the rate to $3.8 \mathrm{~Hz} / \mathrm{sec}$, which is the lowest rate (see Table III).

Figures 17 and 18 show the rotor speed deviation and the change in active power of DFIG WFA1, during the frequency drop, respectively. The deceleration of the rotor results in the active power surge, as kinetic energy of the rotor mass is delivered to the grid as active power.

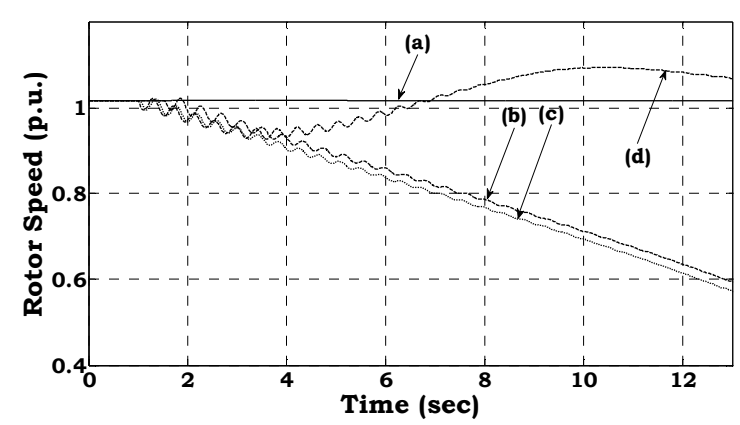

Figure 17. Rotor speed deviations after largest unit loss for different frequency control methods applied in DFIGs - (a) No auxiliary control, (b) Droop control on WF level, (c) Droop control on WT level, (d) Inertia control



Figure 18. Change in active power output after largest unit loss for different frequency control methods applied in DFIGs - (a) No auxiliary control, (b) Droop control on WF level, (c) Droop control on WT level, (d) Inertia control

Table III summarizes the results for the different frequency control methods focusing on the maximum rate of change of frequency (in absolute values), the minimum frequency after the fault and the corresponding load shedding.

TABLE III

RESULTS FOR LOSS OF LARGEST INFEED

\begin{tabular}{|c|c|c|c|c|}
\hline \multicolumn{2}{|c|}{$\begin{array}{c}\text { Frequency } \\
\text { Control } \\
\text { Scheme }\end{array}$} & $\begin{array}{c}\text { Minimum } \\
\text { Frequency } \\
\text { (Hz) }\end{array}$ & $\begin{array}{c}\text { Maximum } \\
\text { Rate of } \\
\text { change of } \\
\text { frequency } \\
\text { (Hz/sec) }\end{array}$ & $\begin{array}{c}\text { Load } \\
\text { Shedding } \\
\text { (MW) }\end{array}$ \\
\hline (a) & $\begin{array}{c}\text { No } \\
\text { auxiliary } \\
\text { control }\end{array}$ & 48.28 & -5 & 15.1 \\
\hline (b) & $\begin{array}{c}\text { Droop } \\
\text { control } \\
\text { on WF } \\
\text { level }\end{array}$ & 48.58 & -5 & 0 \\
\hline (c) & $\begin{array}{c}\text { Droop } \\
\text { control } \\
\text { on WT } \\
\text { level }\end{array}$ & 48.69 & -5 & 0 \\
\hline (d) & $\begin{array}{c}\text { Inertia } \\
\text { control }\end{array}$ & 48.50 & -3.8 & 0 \\
\hline
\end{tabular}

\section{CONCLUSIONS}

The main dynamic security issues of interconnected power systems under increasing wind power penetration were investigated in this paper. The model developed 
includes three types of conventional units and three types of wind turbines. The maximum wind power penetration scenario was presented and the under/over voltage and frequency protection system was added providing accurate results for the load shedding.

The power fluctuations which follow wind speed variations were simulated using the CorWind wind speed simulation tool. The results showed that the frequency fluctuations resulting from the wind speed fluctuations are not considered high enough to pose security questions for the power system. However, the impact of wind variations is obvious in the system frequency and the correlation between wind speeds and system frequency has to be always investigated before reviewing the penetration levels. Increased wind power penetration does not only limit the ability of thermal plants to undertake power, but also limits inertia.

The system operation was also investigated during low voltages conditions. In most non interconnected power systems due to lack of specific grid code the load shedding following fault events is often and severe. Wind farms are still allowed to trip when low voltage is detected at the Point of Common Coupling. In case of a short circuit at the grid the system encounters probable additional loss of production, leading to further stress in the dynamic security of the system in terms of frequency stability. When wind farms are equipped with fault ride through capability, the load shedding following frequency drops is decreased and the wind farms can resume their operation contributing to the system security. DFIG and PMSG wind turbines can contribute to system stability by adjusting their reactive power production during low voltage instances. Advanced power electronic technology provides with sophisticated voltage control capabilities, similar to conventional power plants.

Increasing penetration levels raise the issue of auxiliary frequency control provided by modern wind turbine technology especially in power systems with limited inertia. The simulation results showed that DFIG wind turbines, when equipped with auxiliary frequency control, can provide with valuable active power response during the first seconds following the frequency event. Wind turbines can thus participate in the primary control service of the system, stabilizing frequency after deviations i.e. due to loss of generation. Inertia and Droop control were implemented and proved to be efficient in improving the system frequency response. The rate of change of frequency is reduced when Inertia control is applied, while Droop control benefits in terms of minimum frequency level after the event. In the scenario presented, when wind farms produce more than $30 \%$ of the total demand, auxiliary frequency control implemented in two wind farms in the Rhodes power system manages to avoid load shedding totally. It is concluded that, penetration levels can be further expanded as long as auxiliary frequency control is provided by wind farms.
VII. APPENDIX

TABLE I

BASIC CHARACTERISTICS OF RHODES POWER SYSTEM IN 2012

\begin{tabular}{|c|c|}
\hline \multicolumn{2}{|c|}{ Rhodes power system } \\
\hline $\begin{array}{c}\text { Max Power Demand } \\
(\mathrm{MW})\end{array}$ & 233.1 \\
\hline $\begin{array}{c}\text { Rated Thermal Power } \\
(\mathrm{MW})\end{array}$ & 322.9 \\
\hline $\begin{array}{c}\text { Rated Wind Power } \\
\text { Generation (MW) }\end{array}$ & 48.8 \\
\hline
\end{tabular}

TABLE II

WIND FARMS IN RHODES POWER SYSTEM IN 2012.

\begin{tabular}{|c|c|c|}
\hline & $\begin{array}{c}\text { Wind } \\
\text { Turbine } \\
\text { Technology }\end{array}$ & $\begin{array}{c}\text { Installed } \\
\text { Capacity (MW) }\end{array}$ \\
\hline Wind Farm A1 & DFIG & 11.05 \\
\hline Wind Farm A2 & DFIG & 5.95 \\
\hline Wind Farm B1 & PMSG & 18 \\
\hline Wind Farm B2 & PMSG & 3 \\
\hline Wind Farm C & ASIG & 11.7 \\
\hline
\end{tabular}

\section{ACKNOWLEDGEMENT}

Research funded in part by EU project UPWIND \# SES6 019945.

\section{REFERENCES}

[1] Ciupuliga AR, Gibescu M, Fulli G, Abbate AL, Kling WL. Grid Connection of Large Wind Power Plants: a European Overview. 8th International Workshop on Large-Scale Integration of Wind Power into Power Systems as well as on Transmission Networks for Offshore Wind Farms 2009, Bremen, Germany.

[2] Margaris ID, Mantzaris JC, Karystianos ME, Tsouchnikas Al, Vournas CD, Hatziargyriou ND, Vitellas IC. Methods for evaluating penetration levels of wind generation in autonomous systems. IEEE PowerTech Conf., Bucharest, June 2009.

[3] Margaris ID, Hansen AD, Cutululis NA, Sørensen P, Hatziargyriou N. Impact of Wind Power in Autonomous Power Systems - Power Fluctuations - Modelling and Control Issues, under review in Wind Energy (Wiley) (2009).

[4] DIgSILENT GmbH. DIgSILENT technical documentationPowerFactory, 2006.

[5] Mantzaris J, Karystianos M, Vournas C. Comparison of Gas Turbine and Combined Cycle Models for System Stability Studies. 6th Mediterranean. Conf. MedPower, Thessaloniki, Greece, 2008.

[6] Cutsem TV, Vournas C. Voltage Stability of Electric Power Systems. Ed. Springer, 1998.

[7] Akhmatov V. Analysis of dynamic behavior of electric power systems with large amount of wind power, PhD thesis, 2003, Ørsted DTU.

[8] Poeller M, Achilles S. Aggregated wind park models for analyzing power system dynamics. $4^{\text {th }}$ international workshop on large-scale integration of wind power and transmission networks, October 2003, Billund, Denmark, DIgSILENT, 10pp.

[9] Jauch C, Hansen AD, Sørensen P, Blaabjerg F. Simulation Model of an Active-stall Fixed-speed Wind Turbine Controller. Wind Engineering, vol. 28, no.2, pp. 177-195, 2004.

[10] Hansen AD, Sørensen P, lov F, Blaabjerg F. Centralised power control of wind farm with doubly-fed induction generators. Renewable Energy, vol 31 (2006), 935-951.

[11] Hansen $A D$, Michalke G. Fault ride-through capability of DFIG wind turbines. Renewable Energy, vol 32 (2007), pp 1594-1610.

[12] Hansen MH, Hansen AD, Larsen TJ, øye S, Sørensen P. Control design for a pitch-regulated variable speed wind turbine. Risø-R1500 (EN), 2005, 84pp. 
[13] Hansen AD, Michalke G. Modeling and control of variable speed multi-pole PMSG wind turbine. Wind Energy, 2008, Vol.11(5), pp 537-554.

[14] Sørensen P, Cutululis NA, Vigueras-Rodriguez A, Madsen $H$, Pinson P, Jensen LE, Hjerrild J, Donovan M. Modelling of power fluctuations from large offshore wind farms. Wind Energy 2008; 11, 29-43.

[15] Sørensen P, Cutululis NA, Vigueras-Rodriguez A, Jensen LE, Hjerrild J, Donovan MH, Madsen $\mathrm{H}$. Power fluctuations from large wind farms. IEEE Trans. Power Systems 2007; 22 , 958-965.

[16] Akhmatov V, Knudsen H, Nielsen AH, Pedersen JK, Poulsen NK. Modeling and transient stability of large wind farms. Electrical Power and Energy Systems 25 (2003), 123-144.

[17] Hansen AD, Michalke G, Sørensen P, Lund T, lov T. Coordinated voltage control of DFIG wind turbines in uninterrupted operation during grid faults. Wind Energy, vol. 10, no. 1, 2007, pp.51-68.

[18] Hansen AD, Michalke $G$. Modelling and control of variable speed multi-pole PMSG wind turbine. Wind Energy, 2008, Vol. 11(5), pp 537-554.

[19] Hansen AD, Michalke G. Multi-pole PMSG wind turbines' grid support capability in uninterrupted operation during grid faults. IET Renewable Power Generation, Nov. 2008.

[20] Ekanayake J, Jenkins N. Comparison of the response of doubly fed and fixed-speed induction generator wind turbines to changes in network frequency. IEEE Trans. Energy Conversion, 2004, 19, (4), pp. 800-802.

[21] Holdsworth L, Ekanayake JB, Jenkins N. Power system frequency response from fixed speed and doubly fed induction generatorbased wind turbines. Wind Energy 2004; 7: 21-35. DOI:10.1002/we.105.

[22] Ramtharan G, Ekanayake B, Jenkins N. Frequency support from doubly fed induction generator wind turbines. IET Renew. Power Gener., 2007, 1, (1), pp. 3-9. 